\title{
Should noninvasive ventilation be considered a high-risk procedure during an epidemic?
}

\author{
John McCracken BA
}

Previously published at www.cmaj.ca

$\mathrm{B}$ efore the outbreak of SARS (severe acute respiratory syndrome) in 2003, there was no evidence to support the claim that the use of noninvasive ventilation may increase the risk of transmitting infectious diseases. This concern, however, became widespread early during the SARS epidemic. ${ }^{1}$ Since that time, pandemic planners around the world have classified noninvasive ventilation as a high-risk procedure that should be used cautiously, if at all, during an epidemic. However, the potential harm of withholding the procedure under such circumstances may outweigh the plausible harm of disease transmission.

Despite the paucity of epidemiologic data, the notion that noninvasive ventilation increases occupational risk has gained currency as "a lesson learned from SARS." ${ }^{\text {.-3 }}$ Today, Ontario's Provincial Infectious Diseases Advisory Committee recommends that noninvasive ventilation should be avoided in patients with febrile respiratory illness. ${ }^{4}$ It advises staff to “... carefully consider the benefit of this procedure for the patient versus the potential occupational risk." Citing this advice, at least one Ontario hospital has written an infection-control guideline that prohibits the use of the procedure for patients with any acute respiratory illness during an outbreak. ${ }^{5}$ The World Health Organization, ${ }^{6}$ the United Kingdom's National Health Agency, ${ }^{7}$ the Hong Kong Lung Foundation ${ }^{8}$ and the American Association of Respiratory Care ${ }^{9}$ have also published guidelines that treat noninvasive ventilation as a highrisk procedure.

It is difficult to challenge expert opinion. However, the evidence against noninvasive ventilation is not convincing. Hui and colleagues' experimental model to assess particle disper$\operatorname{sion}^{10}$ is frequently cited to support the theory that flow from a noninvasive ventilator may increase occupational risk. In their study, the authors introduced smoke into the lungs of a mannequin while noninvasive ventilation was being used. Then they photographed plumes of smoke emerging from the vented mask. Whether a mannequin simulates the use of this ventilation procedure on a live patient is debatable. The model does not reflect the circumstances (coughing, sneezing, speaking) wherein the incidence of particle generation is greatest. Nor did Hui and colleagues compare dispersion between individuals receiving noninvasive ventilation and others not receiving it. During a cough, particles would impact against the inside surface of the mask used to deliver noninvasive ventilation, possibly reducing the number of free particles and their range of dispersion into the environment. Because the peak flow

\section{Key points}

- Current infection-control policies that limit or prohibit the use of noninvasive ventilation as a high-risk intervention are based largely on supposition.

- Withholding the procedure under the current guidelines has the potential for considerable harm.

- In the face of the current influenza $A(H 1 N 1)$ epidemic, research is urgently needed to better inform the debate over whether noninvasive ventilation warrants classification as a high-risk procedure.

- Given the available evidence, the precautionary principle directs us toward the use of noninvasive ventilation during an epidemic.

rates of a cough ${ }^{11}$ can be about 10 times greater than the usual flow rate from a mask on patients receiving noninvasive ventilation, it would seem more logical for caregivers to fear the unshielded cough more than a cough into a mask.

The only study to claim a statistically significant association between the use of noninvasive ventilation and transmission of infectious disease is a retrospective case-control study by $\mathrm{Yu}$ and colleagues. ${ }^{12}$ The authors sought to identify potential risk factors associated with superspreading events during the SARS epidemic in China. They found that the use of oxygen by index patients was more consistently associated with such events than was the use of noninvasive ventilation and that noninvasive ventilation was not a significant risk factor in large superspreading events. These findings contradict the authors' contention that the flow of gas from respiratory devices is a cause of disease transmission, because portable bilevel ventilators typically generate higher flow rates than are used to deliver oxygen. Moreover, patients who receive noninvasive ventilation would be expected to have more severe illness and higher viral loads ${ }^{13}$ than would patients treated with oxygen alone. Because noninvasive ventilation was not found to be a significant risk factor in large superspreading events, one could hypothesize that its use may have afforded bystanders some protection against infectious aerosols.

The addition of noninvasive ventilation to standard therapy is

John McCracken is with the Department of Respiratory Therapy, Peterborough Regional Health Centre, Peterborough, Ont.

Cite as CMAJ 2009. DOI:10.1503/cmaj.081987

All editorial matter in CMAJ represents the opinions of the authors and not necessarily those of the Canadian Medical Association. 
associated with lower rates of endotracheal intubation and decreased mortality. These benefits have been well documented among patients with exacerbations of chronic obstructive pulmonary disease and congestive heart failure. ${ }^{14}$ Similar findings were noted among SARS patients who received noninvasive ventilation for acute hypoxic failure..$^{15}$

During an epidemic, it is not always possible to quickly distinguish infected patients from uninfected patients. The specific cause of respiratory failure may be uncertain initially, with patients typically presenting with a constellation of poorly defined signs and symptoms such as fever and radiographic infiltrates. Therefore, the broad restriction of noninvasive ventilation would increase the risk that patients eligible for the procedure may deteriorate to the point of requiring invasive ventilation. Given the complications associated with endotracheal intubation, ${ }^{14}$ restrictions on the use of noninvasive ventilation may result in a substantial number of avoidable deaths.

Some experts have suggested that exhaled gases be filtered and extreme isolation measures be used for patients who receive noninvasive ventilation. However, imposing additional precautionary measures would inhibit the use of this procedure or result in its suboptimal application. Ultimately, further research is required to inform the debate over whether these measures are justified, or whether they represent inappropriate constraints on an important intervention.

Research may provide caregivers with valuable information to guide practice during future epidemics. But how should we proceed during the current influenza $\mathrm{A}(\mathrm{H} 1 \mathrm{~N} 1)$ epidemic? The precautionary principle is widely accepted as a cornerstone of public health policy. As stated by the SARS commissioner: "Yesterday's scientific dogma is today's discarded fable. When it comes to worker safety in hospitals ... we should be driven by the precautionary principle that reasonable steps to reduce risk should not await scientific certainty." ${ }^{\prime 6}$ During the SARS epidemic, the suggestion that noninvasive ventilation may increase the risk of disease transmission was considered sufficient justification to avoid its use. However, in the 6 years since then, no convincing evidence has substantiated that theory. On the other hand, noninvasive ventilation has been proven to save the lives of some patients in acute respiratory failure.

During an epidemic, hospital workers are at increased risk of being exposed and becoming infected. However, it is unclear whether noninvasive ventilation will increase this risk. What is clear is that it is in no one's best interest for patients to undergo endotracheal intubation in cases where it could be avoided. In light of the available evidence, the precautionary principle would suggest that it is imprudent for policy-makers to await scientific certainty. If the demand for sophisticated ICU ventilators threatens to exceed supply during an infectious outbreak, the expeditious use of noninvasive ventilation would help conserve that equipment for those who need it most.

This article has been peer reviewed.

Competing interests: None declared.

Acknowledgement: The author thanks Dr. Karen E.A. Burns in the Division of Critical Care, St. Michael's Hospital, Toronto, Ont., for critically reviewing the manuscript before publication.

\section{REFERENCES}

1. Saint Jacques AJ. SARS outbreak in Canada: an expert interview with Randy Wax, MD, FRCPC. Medscape Med News 2003;Apr.

2. Grossman RF. Alternate modes of ventilation during a pandemic epidemic, pros and cons (slides with transcripts) from: an update on seasonal and pandemic influenza readiness and treatment. Medscape Today 2008; Jan.

3. Nan-Shan Z, Guang-Qiao Z. Pandemic planning in China: applying lessons from severe acute respiratory syndrome. Respirology 2008;13(Suppl 1):33-5. Available: www3 interscience.wiley.com/cgi-bin/fulltext/119415221/PDFSTART (accessed 2009 July 9).

4. Provincial Infectious Diseases Advisory Committee (PIDAC). Preventing febrile respiratory illnesses. Ottawa $(\mathrm{ON})$ : Ontario Ministry of Health and Long-Term Care; 2006. Available: www.health.gov.on.ca/english/providers/program /infectious/diseases/best_prac/bp_fri_080406.pdf (accessed 2009 July 27).

5. Infection control guidelines for use of non-invasive ventilation (BiPAP) in the emergency department and intensive care unit [CPG no. 2-3]. Toronto (ON): Credit Valley Hospital; 2005. Available: www.cvh.on.ca/pro/cpg.php (accessed 2009 July 9).

6. Clinical management of human infection with avian influenza A (H5N1) virus. Updated advice 15 August 2007. Geneva (Switzerland): World Health Organization; 2007. Available: www.who.int/csr/disease/avian_influenza/guidelines /ClinicalManagement07.pdf (accessed 2009 July 9).

7. Pandemic influenza: guidance for infection control in critical care. London (UK) Department of Health; 2008. Available: www.dh.gov.uk/en/Publicationsandstatistics /Publications/PublicationsPolicyAndGuidance/DH_084178 (accessed 2009 July 27).

8. Practice standards of respiratory procedures: post-SARS era noninvasive positive pressure ventilation. Kowloon (Hong Kong): Hong Kong Lung Foundation; 2005. Available: www.hklf.org/HKLF/consensus_NPPV_e.php (accessed 2009 July 9).

9. Non-invasive ventilation [addendum no. 2]. In: Guidelines for acquisition of ventilators to meet demands for pandemic flu and mass casualty incidents. Irving (TX): American Association of Respiratory Care; 2006. Avaialble: www.aarc.org /resources/vent guidelines_08.pdf (accessed 2009 July 9).

10. Hui DS, Hall SD, Mathew TV, et al. Noninvasive positive pressure ventilation an experimental model to assess air and particle dispersion. Chest 2006;130:730-40.

11. Sivasothy P, Brown L, Smith IE, et al. Effect of manually assisted cough and mechanical insufflation on cough flow of normal subjects, patients with chronic obstructive pulmonary disease (COPD), and patients with respiratory muscle weakness. Thorax 2001;56:438-44.

12. Yu IT, Xie ZH, Tsoi KK, et al. Why did outbreaks of severe acute respiratory syndrome occur in some hospital wards but not in others? Clin Infect Dis 2007;44: 1017-25.

13. Chen MIC, Chow ALP, Earnest A, et al. Clinical and epidemiological predictors of transmission in severe acute respiratory syndrome (SARS). BMC Infect Dis 2006; 6:151. DOI:10.1186/1471-2334-6-151.

14. Girou E, Schortgen F, Delclaux C, et al. Association of noninvasive ventilation with nosocomial infections and survival in critically ill patients. JAMA 2000;284:2361-7.

15. Zhao Z, Zhang F, Xu M, et al. Description and clinical treatment of an early outbreak of severe acute respiratory syndrome (SARS) in Guangzhou, PR China. J Med Microbiol 2003;52:715-20.

16. Campbell A. SARS Commission final report: spring of fear. Ottawa (ON): The SARS Commission; 2006. p. 1-1204. Available: www.health.gov.on.ca/english/public /pub/ministry_reports/campbell06/online_rep/index.html (accessed 2009 July 9).

Correspondence to: Mr. John McCracken, Department of Respiratory Therapy, Peterborough Regional Health Centre, 1 Hospital Dr., Peterborough ON K9J 7C6; john.mccracken@sympatico.ca 